\title{
Care and Support for the Elderly in Nigeria: A Review
}

\author{
Judith Ifunanya Ani \\ Department of Sociology \\ University of Ibadan \\ Ibadan
}

DOI: $10.36108 / \mathrm{NJSA} / 4102 / 12(0110)$

\begin{abstract}
This paper presents a review of works on care and support for the aged which is apt for current academic and public policy discourse in Nigeria. The major focus explicated in this review include the concept of care and support, overview of ageing, features and problems of ageing, nature and sources of care and support, the extent to which the elderly depend on their children/extended family, work and old age. It is evident from the review that the traditional norms on care and support for the elderly in Nigeria are waning. It also showed a dearth of public policy on ageing in Nigeria which perhaps could be attributed in part to the young population structure of the country irrespective of the imminent quantum leap of the elderly population in the near future. Despite the decline in traditional norms, the majority of the elderly continue to depend on their children for care and support. The explanations of the decline are attributed to some theoretical viewpoints, including disengagement and modernization theories, and the political economy perspective. This review concludes that there is an urgent need for public policy on ageing in Nigeria to avert the inevitability of poverty and other corollary to it. The policy nonetheless should also be gender-sensitive.
\end{abstract}

Keywords: elderly, care and support, public policy, pension scheme, retirement

\section{Introduction}

Ageing is a global phenomenon and the population of the elderly, people aged 60 years and over, is growing rapidly. Evidently, the world's aged increased from 130 million in 1950 to 419 million in 2000, a proportional share increase from 4 per cent to 7 per cent respectively (Waite, 2004). Nearly 10 per cent of the world's population or over 600 million persons are over the age of 60 , and this is expected to double by 2050. About two-thirds of these 600 million persons live in developing countries (Schwarz, 2003).

Nigeria is the most populous country in Africa and one of the most populous countries of the world. The 2006 population census recorded about 140 million Nigerians, with a population growth rate of 3.2 per cent per annum (NPC, 2006). It is projected that the population will increase to 169.9 million in 2012 and 187 million by 2015 (NPC, 2009). Nigeria has a youthful population. The 1991 population census reported that about 44 per cent of the population is under the age of 15 years; adolescents (ages 10-19) made up 23 per cent of the population, while young people (ages 10-24) accounted for about 32 per cent of the total population (NPPSD, 2004). About 5 per cent of the Nigerian population is aged 60 years and over (NPPSD, 2004). This may have informed the dearth of policy on ageing in Nigeria. However, evidence 
has shown a high prospect for quantum leap of the elderly population in Nigeria.

The United Nations in the 1980s projected that by 2025, the number of the aged in Nigeria would have risen from its $27^{\text {th }}$ position in the $1950 \mathrm{~s}$ to $11^{\text {th }}$ position (United Nations, 1985). Estimates by the United Nations (2012) showed that the elderly population in Nigeria will increase from 6.4 million in 2005 to 11.5 million in 2025, and then 25.5 million by 2050 .

Unfortunately, ageing in developing countries like Nigeria is occurring against a backdrop of dwindling financial resources, very little formal arrangement for support of the elderly, lack of or very weak infrastructures to address emerging issues on aged care and support unlike in developed countries that had a gradual population ageing with an almost resolved issues on infrastructure, maternal and infant mortality (Togonu-Bickersteth and Akinyemi, 2014). Research findings have always stressed the need for care and support of the aged. According to UNESCAP (1994), care and support of the elderly requires that adequate welfare be provided at family and community levels by strengthening family support and developing community-based programmes. Such includes issues on housing, health, medical and nutritional care, income and maintenance as well as personal social services.

This paper undertakes a review of care and support of the elderly in Nigeria by taking an in-depth retrospective outlook of the traditional care and support of the elderly and juxtaposing it with the situation in contemporary Nigeria.

\section{Concept of Care and Support}

Operationally defined, care refers to the attention given to the elderly which could be long-term or short-term care. These range from health care and social services. It could be community-based-care or institutionalized care. Some of these, as Aronson and Neysmith (1997: 38) stated, range from "acute, chronic and rehabilitation hospitals for elderly people who are ill, nursing homes for the elderly requiring fairly constant care and support, health and social programs (e.g. visiting homemaker services, visiting nursing care, day care, meals on wheels, etc.) that allow people with various degrees of health problems and functional limitations to receive care in their own homes." Care requires propinquity or closeness and attention. It also includes all forms of services such as health or nursing care, emotional counselling, etc. On the other hand, support refers to material help or gifts in form of money or goods. It does not demand physical presence or propinquity. Operationally, while care may be referred to as services rendered, support refers to as gifts or materials provided.

Health status of the aged is a function of the care and support they receive. Several chronic diseases suffered by the aged are traceable to lack of or inadequate care and support as well as poor nutrition and physical inactivity (Olayiwola et al., 2010). In Nigeria, evidence shows a very weak institutional base to tackle the care and support of the elderly. 


\section{Overview of Ageing in Nigeria}

Ageing is a biological phenomenon but in a country like Nigeria where cosmological importance is attached to several social facts, it is both a biological and social phenomenon. According to Togonu-Bickersteth and Akinyemi (2014: 363), "it is not just a natural process that reflects biological and physiological changes but a social fact with significant impact on society, community and culture." The Nigerian traditional family structure was patriarchal and characterized by an extended family system. It was a close-knit social unit which emphasized care and support for the elderly members in terms of food supply, welfare, security, etc. Elderly care did not pose any challenge because of the kinship ties that bonded family members. The elderly were seen as a veritable source of wisdom and knowledge for guidance and direction in the traditional Nigerian society and they were also held in a very high esteem (Wahab and Isiugo-Abanihe, 2008).

Old age was reckoned as a stage of great wisdom with a high social honour/importance attached to it. This is not bereft of rites of passage used to mark transition from one stage in life to another in many Nigerian societies (Togonu-Bickersteth and Akinyemi, 2014). As identified by the author, among the Ngwo people of the Ibo tribe in South-eastern Nigeria, they practice several ceremonies to mark transition to old age for both male and female. There is the Ori na ndu and Adu Kwurum ceremony which is done for women who lived to see their grandchildren; Ori Enya ceremony for titled aged women and Amushi for aged male. The Ero festival as identified by Togonu-Bickersteth and Akinyemi (2014) is practiced among the Owo people of the Yoruba tribe in South-western Nigeria. These festivals mark the importance attached to old age as a time of responsibility, respectability, wisdom and the aged as traditional consultants for the younger members of the society. Traditional society believed in ageing with dignity and emphasized the importance of having a good life and good wellbeing in old age. People often say that "it is better to die young with dignity than to die old in abject poverty." As TogonuBickersteth and Akinyemi (2014) commented, this does not underrate the importance of old age among the people but the need not to get to old age in poverty. Therefore, ageing was viewed as a stage in life where the elderly should be wealthy and not poor, hence, the importance attached to the elderly care and support in traditional days.

The elderly were seen as custodians of culture and tradition. As Hatendi (2014) stated, they are the guardians of Africa history and culture, and they play a vital role during natural or humanitarian emergencies. They also fosterin or look after grandchildren, which also ensure their own survival (Bledsoe and Isiugo-Abanihe, 1987). However, the traditional extended family which emphasized respect and assistance for the elderly has been eroded by a nuclear family system, rapid economic growth, migration of young members to seek for employment and career opportunities, urbanization and industrialization, 
change in the traditional role and status of the elderly in the society, advent of new religions where access is no longer through the ancestors, etc. (Abdulrahman, 1988; ESCAP, 1994; Togonu-Bickersteth and Akinyemi, 2014).

\section{Features and Problems of Ageing}

Ageing diminishes the capacity to work and it is also a stage of several vulnerabilities (Kakwani and Subbarao, 2005). According to Marshall (1985), the elderly are usually the disengaged or decrepit that must be supported by families and/or community. Some of the salient features of this population are a dependent population, a period for the onset of some chronic diseases, a population with special needs, care and support ranging from health, financial, emotional and psychological needs.

The majority of the elderly are unable to access health care due to its cost. Most of them are limited by out-of-pocket payment arrangement, dearth of health care facilities and a dwindling social network to offer support as in the traditional times. Gureje and Oyewole (2006) were of the view that implicit social changes reduce the status of the elderly and their influence in the society which affect their total wellbeing. The elderly, in a country like Nigeria without a policy for the aged, are at a high risk of ill-health and disability particularly from chronic non-communicable diseases and as a result of lack of access to health care. The majority of them are faced with depression, loss of vision, diabetes, hypertension, obesity, tooth loss, pathological bone fracture, arthritis and rheumatism, stroke, Alzheimer's disease, etc.

Ageing predisposes the majority of the elderly not just to sickness but also social and economic problems as Gureje et al. (2008) submitted. Accordingly, the elderly are prone to poverty because of their economic redundancy in a society with no social pension for them. The elderly, according to HelpAge International (2002), are mostly the poorest members of the society who live below poverty line. This poverty, as Jackson (2002) argued, translates into poor health and nutrition, income insecurity, enormous burden in dealing with the scourge of HIV/AIDS pandemic, psychological pressures, violence and homelessness. They also face other challenges such as compulsory retirement, lack of preparation for retirement, inadequate financial provisions, problems of loneliness and isolation. Extra cost of dependency and disability threaten the elderly and even their families whose present or future income security may be threatened as time spent in caregiving may interfere with their capacity to earn income (Jenson and Jacobzone, 2000).

\section{Nature and Sources of Care and Support}

Operationally, the nature of care and support refers to the kind of care and support received by the elderly; it could be financial, domestic assistance, health care, etc. Source of care and support refers to the provider of care and support, which could be the government through the pension scheme, family 
members, community, church, mosque, etc. Nature and sources of care and support are dependent upon several socio-demographic features.

In Nigeria, the amount of care and support to be received by the elderly is a function of the level of the child's education and the nature of the child's occupation. For example, the study by Peil (1991) showed that a lower level of education and certain kinds of occupation correlate with little or no support from children to the elderly parents. Children who were farmers were less likely to provide support for their parents, and children with secondary school or lower education were also less likely to give any material support to their parents. Also, those who are not in any wage employment live with their elderly parents who support them.

In the traditional times, the aged were totally cared for and supported because customs and traditions required that such be done. Such roles and expectations of the younger generations were deeply entrenched in everyday proverbs. For example, the Yoruba of the South-Western Nigeria say that, "When the bush rat gets old, it feeds on its children's breast" (TogonuBickersteth and Akinyemi, 2014). Such emphasis is not peculiar to Nigeria alone. It transcends to other African countries as Apt (1996) asserted that in Ghana, it is usually said that 'when your elders take care of you when you cut your teeth, you must in turn take care of them while they are losing theirs.'

Family members were pivotal in providing care and support for the elderly (Unanka, 2003; Cattel, 1990). Lopata (1973), in a study found that the extended family functioned effectively in providing care and support for the elderly. They provided emotional, social and financial support to the aged especially when they were facing widowhood and bereavement. Peil and Sada (1984) added that visits served as an occasion for providing material help and was necessary for social and psychological support. According to Aboderin (2004), childlessness was not a reason for non-support and care. The extended family system which was prevalent stood in for the childless individuals or couples.

In traditional Nigerian societies, cost of living was very low compared to the present day economic austerity. Family members pulled resources to cater for expensive needs. Care and support for the aged by children was clearly based on reciprocity to parents for care they received as children and purely as a sense of duty. This is in line with Gouldener's $(1960 ; 1973)$ submission about norms of reciprocity and status duty. Children helped their aged parents because it was scriptural to do so and for them (children) to also receive help when they (children) need it. They also did that to avoid being reprimanded for not doing so. Religious and philosophical attributes were attached to care and support for the aged. This reveals complex social, cultural and ideological realities inherent in Nigeria as well as other parts of Africa where spiritual and economic rewards were attached to care and support for the aged. 
For example, Aboderin (2004) stated that people often cited the scriptural evidence which compelled them to provide care and support. Accordingly, they believed in the commandment in Exodus 20:12 which says, 'Honour your father and your mother that your days may be long in the land that the Lord your God is giving you.' Also, the Ibos of the South-eastern Nigeria believe so much in the existential reality that 'what goes around, comes around.' They also say that 'one hand can never wash itself, therefore, the left washes the right and the right washes the left.'

However, these have changed in contemporary Nigeria. More so, Hatendi (2014) submitted that psychosocial support is very limited for the elderly who are saddled with the responsibility of raising grandchildren in a digital world. Obviously, the majority of the aged population cannot access the internet, use cell phones or operate the computer. By implication, there is a wide intergenerational gap between these parents and their grandchildren. In Nigeria, this gap is wide as digital revolution was experienced barely 13 years ago starting from the year 2001 when GSM use in Nigeria started.

\section{Dependence on Children/Extended Family}

Traditionally in Nigeria, high fertility was rational and existed in a setting that accorded high spiritual and economic importance to marital fertility (Caldwell and Caldwell, 1987). In his intergenerational wealth flow theory, Caldwell (1976) linked family structure and wealth flow and established the perceived benefits of high fertility in the traditional society. In traditional society, there was an upward flow of wealth, that is, wealth flowed from children to parents. Based on this, a large household was maintained such that the status of the head of the household depended on the number of children. Children were also seen as an economic investment for parents in old age (Wahab and IsiugoAbanihe, 2008; 2010). This was partly responsible for having a large number of children on whom to depend on for sustenance in old age (Isiugo-Abanihe, 1994). The different advantages parents gained from children included the following:

- Parents controlled and had access to more services if the number of children and grand-children were large.

- Children worked in the household, did chores such as fetching water, firewood or other fuel for cooking, swept the compound, cared and nurtured the younger ones and even tended the family animals, etc.

- Adult children worked in the farms as labourers by planting and harvesting for their parents. They were very helpful during ceremonies such as funerals, marriages, and festivals.

Obviously, some of these issues have undergone changes in present-day Nigeria, especially in the context of poverty and other consequences of poverty. With the high level of youth unemployment, children may not be economically buoyant to support their elderly parents; rather the elderly tend to 
support their children longer than was the case in the past (Togonu-Bickersteth and Akinyemi, 2014). The elderly no longer depend on their children/extended family extensively for chores and other forms of domestic assistance due to a very high rate of out-migration from rural areas. Nevertheless, the majority of the elderly in Nigeria continue to receive some support from their children irrespective of the decline in the traditional family backings and in the absence of adequate formal sources of care and support (Apt, 1992). The majority of the elderly are impoverished and abandoned, leaving their care and support to charity organizations. For example, Aboderin (2004) noted charitable organization such as HelpAge International which emerged to support and care for the aged especially those abandoned in the hospitals by their families.

The declining care and support for the elderly according to Aboderin (2004) may result to income insecurity. The reality of this situation has prompted some countries such as South Africa, Brazil, Botswana and India to institute the non-contributory social pension scheme. Currently in Nigeria, only two states out of the 36 states and the Federal Capital Territory have commenced this programme. They include Osun State and Ekiti State in the South-western Nigeria. Some of the elderly therefore tend to take up work at old age to augment whatever they get from their children.

\section{Work and Old Age}

Ageing has both biological and social realities. The biological reality of old age is the onset of some degenerative diseases and stage of becoming frail, while some of the social aspects is the stage of retirement and sometimes experience of aggression (Mucha and Krzyżowski, 2010). According to Atchley (1977), retirement is the act of retiring or a state of being retired which means the withdrawal of oneself from business, public life or active service. Retirement has also been viewed as a stage of transition whereby the retiree moves from former business career of active services to another stage of life development (Omoresemi, 1987).

The elderly in some developed countries continue to work even after age 65. In Japan, the labour force participation of the elderly aged 65 and above is high; about 85 per cent of men aged 55-64 and one-third of all elderly aged 65 and above continue to work (Kinsella and Gist, 1995). In Africa, about 30 per cent of women and 50 per cent of men continue to work even at age 65 and above and the majority of these are rural dwellers who coincidentally are farmers (Hatendi, 2014). In Nigeria and other developing countries, work participation of the elderly is higher than those of the industrialized nations due to limitations of retirement coverage and social support (Kinsella and Gist, 1995). According to the NPC (2009), most of the elderly in Nigeria continue to participate in the labour force even in their old age and toward the end of their lives. The National Bureau of Statistics (2011) stated that about 67 per cent of the adult population in Nigeria are engaged in informal sector, which is not 
covered by the pension scheme, and unemployment rate for the country was about 23.9 per cent in 2011. This further attenuates the prospect for care and support for the elderly, making them to continue to work after retirement until they are too weak to do so.

With about 70 per cent of Nigerians living below poverty line (NPC, 2004), there is the tendency that even after retirement, retirees may continue to work especially in the informal sector. Given that the substantial proportion of the working-group population are not financially buoyant due to unemployment, the pursuit of education, etc., the elderly stand in to provide support in form of direct financial assistance, housing accommodation, child care, house maintenance, etc. (Blieszner and Bedford, 1995; Apt, 1992; Hashimoto, 1991). Work done by the elderly is with the aim to sustain themselves and household members who are either young dependents or adults who are unemployed. These elderly individuals may work for the money or the materials to be gained. Peil (1991) and Bledsoe \& Isiugo-Abanihe (1987) have showed that the elderly in West Africa usually provide care for their grandchildren, and many others send gifts to other children; most of them in the rural areas work into their 80's mostly looking after grandchildren in return for gifts which may be either cash or goods (Peil, 1991). Togonu-Bickersteth and Akinyemi (2014) noted that without savings and support, they fall back to the street begging for alms. According to Togonu-Bickersteth et al. (1997), about 50 per cent of elderly males of Yoruba origin and 68 per cent of elderly females begged for alms not because they had no child(ren) or close relatives, but because they received no support from their adult children.

\section{Changes in Patterns of the Aged Care and Support}

Several socio-demographic variables have influenced care and support given to the elderly in contemporary Nigeria. The gerontological literature has lent credence to the declining care and support for the elderly and attributed it to factors such as high rate of unemployment, inadequate resources, nuclerization of families, increasing demands for leisure, cost of acquiring western education, migration of the younger relatives, changes in living arrangements and household types, HIV/AIDS pandemic, modernization and globalization, economic constraint, marital status, etc. Modern day realities are inconsistent with Peil's (1991) submission that there is a presence of a strong family support networks in Nigeria as the majority of the elderly are getting adequate assistance from their children, siblings and other relatives. However, Wahab and Isiugo-Abanihe (2008) submitted that elderly care among the Ijebu rests on the elderly' ability to save and make some investments for old age and against poverty; they also found that certain socio-demographic characteristics influence lifetime investments in anticipation of old age. With economic depression and compulsory statutory retirement age in Nigeria, many older adults are forced out of work before they could make enough investment in anticipation of old age, thereby, increasing their chances of poverty (Isiugo- 
Abanihe and Wahab, 2008). Although culturally determined, familial care and support is socially reinforced (Neysmith and Edward, 1999; Kalache 1990).

Several scholars in the 1950s and 1960s observed that the extended family structure was disintegrating into a small and autonomous nuclear family (Parsons, 1959; Burgess, 1960; Goode, 1963). Cowgill (1974) attributed this to modernization especially as urbanization and mass education create social, intellectual and geographical distance among family members. Implicitly and consistent with modern day realities in Nigeria, the elderly are not only separated from their children/extended families at these three levels but also experience decline in their care and support. In a study conducted by Aboderin (2004), it was evident that there is a decline in material family support for the older people, which expose them to destitution and poverty. Overtime, this decline has been neglected in Nigeria, as Togonu-Bickersteth and Akinyemi (2014) put it, either through sheer negligence from the government, unholistic analysis of the problems in old age or the assumption that "things will sort themselves out."

In her findings, Aboderin (2004) noted that care and support have declined in two ways. The first is that older adults are left to fend for themselves as the extended families no longer provide care and support, and those provided by children are not enough. This was caused by scarce resources and rising cost of living which inform a rational decision of placing priority on immediate family members comprising of self, spouse and children. In his classical statement, Veblen (1899) stated that in a modern industrial society, people engage in conspicuous consumption and conspicuous leisure. These also may be competing for scarce resources. There is an increasing demand to buy material things such as cars and other forms of assets. Aboderin (2004) findings lent credence to this view as there is now a shift from the traditional and customary care and support for the elderly to a new emphasis on material possession or goods, lifestyles and technology.

Secondly, spatial location also impacts on the care given to the aged. The elderly experience an 'Empty Nest Syndrome' as the quest for employment has pushed children away from parents. Therefore, the physical separation of parents from their children due to urbanization and migration has far reaching implications for the elderly care and support in Nigeria. Most of the prime age children live in the urban centres where they seek employment or other corollary to migration. With increase in migratory flow which is highly agedependent, there is little or no attention given to elderly parents. Even when such aged or elderly parents move to the urban centre to reside with their children, they tend to be lonely or neglected because their sons and daughters usually leave for work early in the morning and come back in late the evening.

The decline in care and support for the elderly could also be attributed to a rational choice. In his theoretical postulation, Coleman (1990) was of the view that societal outcomes are products of individuals' values and preferences. 
Due to scarce resources, people make choices on what will give them the greatest satisfaction. Based on this, the younger generations tend to shield off themselves of any conflicting ideas or demands on their resources. Aboderin (2004) shared in this view that material support for the older kin has declined because it conflicts with the younger generations' needs and aspirations, and that the younger generations hold unto ideas that there is no longer fear for sanctions for not supporting the elderly as was prevalent in traditional times.

The AIDS pandemic in Africa is an emerging reason for the declining care and support for the elderly. A large number of the elderly provide care for the younger children who may have been orphaned by the epidemic (Kautz, Bendavid, Bhattacharya, Miller, 2010). The estimate by the Joint United Nations Programme on HIV/AIDS that by 2007, the HIV/AIDS would have orphaned more than 12 million children in sub-Saharan Africa may have materialized as the HIV/AIDS pandemic has changed household structures and the elderly are saddled with the responsibility of caring for orphans (UNAIDS, 2008; Gregson et al., 2007; Kautz et al., 2010). In Nigeria, the HIV prevalence rate increased from 1.8 per cent in 1993 to 5.4 per cent in 1999 and more than 2.7 million Nigerians are infected (NPPSD, 2004), giving rise to a large number of orphans.

Mortality resulting from HIV/AIDS affects mainly the prime age adults (Smith et al., 2007) who are primary caregivers for the elderly (Aboderin, 2004; Barrientos, Gorman and Heslop, 2003). To this end, household structures have changed, either leaving the elderly unattended to or the elderly caring for young dependent children or the elderly living with fewer than necessary prime age adults. Based on this, Kautz et al. (2010) were assertive that the unattended elderly people may be harmed by lack of support from prime age adults. They stated further that in households where children have been orphaned by the disease pandemic, referred to as 'missing generation household', there is an extra burden and cost on the elderly taking care of these children. Kautz et al. (2010) showed that in Nigeria in 2006, between 109,400 to 172,300 elderly were unattended to as a result of AIDS mortality comparable to countries like Madagascar with only 500-700 and Senegal with only 900-1400 unattended elderly as a result of AIDS mortality within the same year.

\section{Implications of Decline in Elderly Care and Support and the Need for a Public Policy}

Jugessur (2000) has observed that in 50 years time, the growth rate of the elderly in Africa as a whole will increase from 4.52 per cent to 11.32 per cent. Despite this demographic "age-quake," as Nyanguru (2003) put it, policy concerns on poverty among the elderly is still not a core concern of social, economic and ethical debates. The former Vice-President of Nigeria, Atiku Abubakar (2014) expressed concerns about the rapid changes in the relative number of the elderly population Nigeria will experience in the coming years. On this, Atiku (2014) asserted that it is necessary as individuals and nations to understand the dynamics of ageing, anticipate the changing needs of the elderly 
and strengthen social institutions and national capacity to address them. Since ageing has left the domain of a personal problem to a public issue, as Mills (1959) in his discourse of sociological imagination opined, it is obvious that the problem of the elderly in Nigeria is a problem to the entire population of the country. The implication therefore is the need for a public policy on ageing in Nigeria which unarguably must be gender sensitive.

The human rights of the elderly in Nigeria are still hampered in the absence of a policy on ageing and in the presence of a declining traditional care and support. The majority of the elderly are subjected to hardship and abuses. Governmental attention should also favour elderly issues as much as it does to children and women issues. It is the duty of the government to protect and promote human rights of every citizen regardless of age, race, gender, education and culture. The elderly who have acquired skills and whose leadership and consultative roles in the society cannot be undermined should have their needs integrated into policy concerns. The older peoples' rights, as captured by the United Nations Principles for Older Persons, must be respected and articulated into social and economic policies. Peterson (2002) divided these principles into five: independence, care, self-fulfilment, dignity and participation.

The policy needs for the elderly population have been echoed in international frameworks such as the 2002 United Nations Madrid International Plan of Action on Ageing and the 2003 African Union Policy Framework and Plan of Action on Ageing. They point towards enhancing health care services for the elderly as part of encouraging their immense contributions in the society at large. The measures called for by the two plans are "a multi-faceted health promotion strategies to prevent disease and disability among successive cohorts of older persons and to ensure full access to adequate curative and rehabilitative care for older persons who already suffer from disease or disability. The goal of which is to enhance older persons' quality of life" (Aboderin, 2010). Some African countries have already begun a free healthcare for the aged. Such countries are South Africa and Senegal. There is an urgent need for all states in Nigeria to adopt same measures in line with the international frameworks. It is in this regard that the recent disbursement of old age support by Ekiti and Osun States is most commendable. Other states, as well as the federal government, should follow suit.

\section{Theoretical Explanations}

Given the inherent changes in elderly care and support in Nigeria in relation to the nature and sources of their care and support, the extent to which they depend on their children/extended family and the tendency of continuing to work even after retirement, debates have geared towards providing a grand nomothetic explanatory framework. This includes ageing theories with particular reference to the disengagement theory and modernization theory, the 
Marxist school of thought whose interpretations were drawn from the political economy perspective. The explanatory frameworks are essentially macro sociological perspectives and implicate declines in traditional family support to the elderly to the emergence of industrialization, globalization, urbanization, nuclerization of families as well as global economic recession, etc. The disengagement theory was used to explain retirement of the elderly, while the modernization perspective was used to explain causes of decline in elderly care and support as well as loss of the elderly status. The political economy perspective explained the reality of economic development and how it has posed a serious economic constraint making it difficult for children to provide adequate support to the elderly in a capitalist global economy.

The disengagement theory put forward by Cumming and Henry (1961: 24) in their seminal book Growing Old, posited that "disengagement is an inevitable process in which many of the relationship between a person and other members of society are severed and those remaining are altered in quality." The theory argued that by the sixth decade of life, that is, about the age of 60 , individuals begin to withdraw from those interactions that defined their life and which is seen by the society as desirable, inevitable and mutual. This withdrawal is implicit in retirement.

Due to the inevitability of death, the society and the individual in advance sever their ties to avoid disrupting the social system, and lessening social interaction leads to the weakening of norms guiding interactions between the society and elderly individuals (Quadagno, 2008). To the extent that society offers the elderly the "permission" to disengage, scholars were of the view that the society uses pension to keep the elderly out of the labour force so that younger people can take over their positions. This shows clearly how the elders are made to retire from their work role. This theory assumed that it is necessary for the elderly to retire at certain age so that younger individuals can take over their jobs.

This theory has been criticized on the ground that it contains bias against the elderly who are seen as sinking into oblivion or decrepitude when they disengage from an active social life. The elderly however enter into new roles which are more or less an exchange of one role for another. They enter into roles which centre on friendship which is as satisfying as the first set of roles (Jerome, 1992). This perhaps also explains work after retirement as a means of continuing familiar activities of the middle-age. In Shanas' (1965) view, the theory implies the desirability of disengagement and therefore makes allowances for the neglect of the elderly as well as creating a sense of apathy towards the challenges of the older people.

Modernization theory as proposed by Cowgill and Holmes (1972) was built on the emergence of four variables - urbanization, economic technology, education and health technology. They were of the opinion that as societies modernized and coupled with the individualistic nature of western society, the status of the elderly depreciated. The modernization theory was premised on the ground that there was once a golden age of ageing where family members 
lived together in a household ruled by the aged. These elderly individuals were highly venerated and valued because of the skills which they possessed and transmitted to the younger generations. They also provided leadership in the community until modernization dismantled the traditional society. Work moved people from home to the factories and urbanization pulled young people into the cities, thus, isolating the elderly and dismantling the extended family system (Quadagno, 2008). Quadagno (2008: 58) also observed that "education undermined the mystique of age because children now know more than their parents. The honorific position of older people held as keepers of communal knowledge disappears. The new elite become the young."

With rising acceptance of western values, the bonds in the traditional extended family increasingly became weakened. As secularization and individualism which are the basic tenet of modernization held sway in a modern industrial society, emphasis was laid on nuclear family with a very minimal care and support for the elderly. Latently, the elderly also lost their significant roles and statues. In Chiegwe's (2000: 71) view, "with the breakdown of traditional way of life, more individualistic behaviour patterns and greater secularization were held to arise from growing urban influences and modes of behaviour."

Modernization theory has been criticized as presenting a linear explanation of societal changes and reduced status, care and support of the elderly (Fry, 1996). This theoretical perspective did not also take into account how the global economy and political variations among countries result in different or various policies and conceptualizations (Estes, Wallace and Linkins, 2000).

The political economy perspective belongs to the Marxists school of thought and is sometimes referred to as critical gerontology (Matcha, 2007). It viewed patterns of care and support of the elderly in relation to the outcome of power struggle. This perspective offered a global insight of the conditions of the elderly in a global capitalist economy. According to Estes (1991: 19), "the political economy of ageing offers a theoretical and empirical perspective on the socioeconomic determinants of the experience of ageing and old age and on the policy intervention that emerge in the context of capitalist society." The political economy perspective examines the conditions of the elderly and their relationship to the larger structural constraints of the society (Matcha, 2007).

In adopting this theoretical perspective, Goldstein, Schuler \& Ross (1983); and Treas \& Logue (1986) opined that the harsh reality of economic development in poor countries have placed majority of the population in a weak position in the global economy such that strains are placed on the available resources. With economic stagnation, economic hardship is experienced by majority of the population causing economic constraints and a declining support and care for the aged. By implication, the available resources are prioritized for the immediate nuclear family leaving out the old ones. As a result, decline in care and support of the aged is seen as caused by a growing 
incapacity on the side of the young (Aboderin, 2004). The inability of a large young population to get employment and a well-paid job makes it impossible for them to extend their very limited resources to the older population. However, this theoretical perspective has been criticized by scholars like Phillipson (1998) and Walker (2006) on the ground that it viewed the elderly as being too passive, whose economic and social relationships are solely determined by the state.

\section{Conclusion}

This review presents a strong evidence of the decline in care and support for the Nigerian elderly as well as diminishing status of the elderly in Nigerian contemporary society. This is detrimental to the well-being of the elderly population in Nigeria and poverty among the elderly is imminent. There is need for a policy on ageing in Nigeria which should be mainstreamed into the Post-2015 Sustainable Development Agenda. It is important to re-echo that ignoring sociological insight is ignoring the risk of serious impoverishment in heritage. The elderly need to be taken into cognizance as the elderly are as important as the youths. Issues on ageing should be treated as a human right which indeed is what it is as enshrined in the article 25(1) of the Universal Declaration of Human Right:

Everyone has the right to a standard of living adequate for the health and well-being of himself and of his family, including food, clothing, housing and medical care and necessary social services, and the right to security in the event of unemployment, sickness, disability, widowhood, old age or other lack of livelihood in circumstances beyond his control.

This review highly recommends governmental attention to the elderly in general and not only pension-earners as the majority of the elderly are not pensionable because they did not work in the formal sector. To this end, government should come up with a social pension policy which may be noncontributory to assist the elderly because of their diminished capacity to work and the enormous burden on them in the wake of disease epidemics and other socio-demographic changes. Latently, support given to the elderly will still be ploughed back towards welfare of family members as they are very much likely to be shared among the household. This also has implications for poverty reduction.

There is need for mass enlightenment on active ageing and other issues on ageing. In doing so, socio-demographic characteristics of the aged must be taken into consideration as the needs of the elderly differ by gender, location, education, etc. Policies enacted must be accompanied by a strong political will for implementation while ensuring adequate legislation, accountability and gender sensitive policies. Civil society organization and human rights activists should also take a paradigm shift in articulating procedures of championing 
global ageing policies and at the same time, ageing issues could be inculcated in school curriculum because it is a life course cycle.

\section{References}

Abdulrahman, P.A. 1988. The Sociology of the Ageing Process. A Paper Presented at the Conference on the Aged in Sokoto State.

Aboderin, I. 2004. Modernization and ageing theory revisited: Current explanations of recent developing world and historical shifts in material family support for older people. Ageing and Society. 24: 29-50.

Aboderin, I. 2010. Understanding and Advancing the Health of Older Populations in sub-Saharan Africa: Policy Perspectives and Evidence Needs. Public Health Reviews. 32: 357-76.

Aboderin, I. 2014. Decline in material family support for older people in urban Ghana, Africa: understanding processes and causes of change. J Gerontol B Psychol Sci Soc Sci., 2004. 59: 128-37S.

Anchalesh, K. 2012. The Impact of Globalization on Family Structure: A Sociological Study (in reference to the 300 Bengali Families Situating in Udham Singh Nagar District of Uttarakhand). Journal of Experimental Sciences. 3(1): 10-13.

Apt, N.A. 1992. Family Support to the Elderly People. In Ghana in Kinsella, K. and Gist, Y.J. 1995. Older Workers, Retirement and Pensions. A Comparative International Chartbook. IPC/95-2.

Apt, N.A. 1996. Coping with old age in a changing Africa. Aldershot: Avebury.

Aronson, J. and Neysmith, S. 1997. The Retreat of the State and Long-Term Care Provision: Implications for Frail Elderly People, Unpaid Family Carers and Paid Home Care Workers. Studies in Political Economy. 53.

Atchley, R.C. 1971. The Social Forces in Later Life. 2nd ed. Belmont, California Wards worth.

Atiku, A. 2004. Speech delivered by the Vice President of the Federal Republic of Nigeria on March, 21st 2004 on the situation of Ageing in Nigeria.

Barrientos, A.; Gorman, M. and Heslop, A. 2003. Old age and poverty in developing countries: contributions and dependence in later life. WorldDev. 31: 555-70.

Bledsoe, C. and U.C. Isiugo-Abanihe. 1989. Strategies of Child Fosterage Among Mende Grannies in Sierra Leone. In R. Lesthaeghe (ed.). African Reproduction and Social Organization. Berkeley: University of California Press.

Blieszner, R. and Bedford, V.I. (eds.). 1995. Handbook of Ageing and the Family. Westpost, CT.: Greenwood Press.

Burgess, E. 1960. Ageing in western culture. In E. Burgess (ed.). Ageing in Western Societies. Chicago: University of Chicago Press. 346-358. 
Caldwell, J.C. 1976. Fertility and the Household Economy in Nigeria. Journal of Comparative Family Studies. 7: 193-253.

Caldwell, John C. and Pat Caldwell. 1987. The cultural context of high fertility in sub-Saharan Africa. Population and Development Review. 13(3): 409437.

Cattel, M.G. 1990. Models of old age among the Samia of Kenya: family support of the elderly. J Cross Cult Gerontol. 5: 375-94.

Chiegwe, O. 2000. Studies in Social Change. (1st ed.). Benin: INESTI Typesetting Bureau.

Coleman, J. 1990. Foundations of Social Theory. Cambridge: Harvard University Press.

Cowgill, D O. 1974. Ageing and modernization: A revision of the theory. New York: Appleton-Century-Croft.

Cowgill, D.O. and Holmes, L.D. 1972. Summary and Conclusions: The Theory in Review. In D.O. Cowgill \& L.D. Holmes (eds.). 305-323. Ageing and modernization. New York: Appleton-Century-Crofts. 1-14.

Cumming, E. and Henry, W. 1961. Growing Old: The Problem of Disengagement. New York: Basic Books.

Davis, K. 1959. The Myth of Functional Analysis as a Special Method of Sociology and Anthropology. American Social Review.

ESCAP. 1994. Ageing and the Family in the Developing Asia and Pacific Countries. New York: United Nations. 73-75.

Estes, C.; Wallace, S. and Linkins, K. 2000. Political Economy of Health and Ageing. In Bird, C.E.; Conrard, P. and Freemont, A. (eds.). Handbook of Medical Sociology. 5th ed. Upper Saddle River, NJ: Prentice Hill. 129-142.

Etzioni, A. and Etzioni, E. 1964. Social Change. New York: Basic Books.

Giddens, A. 1990. Sociology. Cambridge: Polity Press.

Goldstein, M.C.; Schuler, S. \& Ross, J.L. 1983. Social and economic forces affecting intergenerational relations in a third world country: A cautionary tale from South Asia. Journal of Gerontology. 38: 716-724.

Goode, W. 1963. World Revolution and Family Patterns. Glencoe, Illinois: Free Press.

Gouldner, A.W. 1960. The norm of reciprocity: A preliminary statement. American Sociological Review. 25: 161-178.

Gouldner, A.W. 1973. For Sociology: Renewal and critique in sociology today. London: Allen Lane.

Gregson, S.; Nyamukapa, C.; Lopman, B.; Mushati, P.; Garnett, G.P. and Chandiwana, S.K. 2007. Critique of early models of the demographic impact of HIV/AIDS in sub-Saharan Africa based on contemporary empirical data from Zimbabwe. Proc Natl AcadSci. USA. 104: 14586-91.

Gureje O. and Oyewole O. 2006. Informal care and the elderly in a changing society: a qualitative study of care recipients and caregivers. Quarterly Journal of Mental Health. 1: 56-61. 
Gureje, O.; Kola, L.; Afolabi, E.; Olley, B. 2008. Determinants of quality of life of elderly Nigerians: results from the Ibadan Study of Ageing. Afr $J$ Med Med Sci. 37(3): 239-247.

Hashimoto, A. 1991. Urbanization and Changes in Living Arrangements of the Elderly, in United Nations Ageing and Urbanization, ST/ESA/SER. R/109, New York.

Hatendi, N. 2014. Older Persons and the Post-2015 Agenda- a sub-Saharan Africa's Perspective. Development dialogue paper. No. 10. June.

HelpAge International. 2002. Ageing and the Development Report: Poverty, Independence and the World's Older People, Eatrthscan.

Isiugo-Abanihe, U.C. 1994. The Socio-cultural Context of High Fertility among Igbo Women. International Sociology. 9(2): 237-258.

Isiugo-Abanihe, U.C. \& Wahab, E.O. 2009. Epistemological advances in studying the demography of ageing. Anthropologist. 11(4): 265-270.

Jackson, H. 2002. Aids Africa: Continent in Crisis, Safaids, Sida, Harare.

Jenson, J. and Jacobzone, S. 2000. Care Allowances for the Frail Elderly and Their Impact on Women Care-Givers, OECD Labour Market and Social Policy Occasional Papers, No. 41, OECD Publishing. http://dx.doi.org/ $10.1787 / 414673405257$.

Jerome, Dorothy. 1992. Good Company: An Anthropological Study of Old People in Groups. Edinburgh: Edinburgh University Press.

Jugessurs, S. 2000. Policy Framework for Ensuring a Regular Income to Older People in Africa. Paper presented at the OAU/HAI Expert meeting Kampala, Uganda, 27-1 December, 2000.

Kakwani, N. and Subbaro, K. 2005. Ageing and Poverty in Africa and the Role of Social Pensions. The World Bank Africa Human Development, March 2005. 32178 Revised Final Version.

Kalache, A. 1990. Ageing in developing countries. In Pathy, M. (ed.). Principles of Geriatric Medicine. New York: John Wiley Press. 93-113.

Kautz, T.; Bendavid, E.; Bhattacharya, J. and Miller, G. 2010. AIDS and declining support for dependent elderly people in Africa: retrospective analysis using demographic and health surveys. BMJ; 340:c2841 doi:10.1136/bmj.c2841.

Kinsella, K. and Gist, Y.J. 1995. Older Workers, Retirement and Pensions. $A$ Comparative International Chartbook. IPC/95-2.

Lipman, A. and Smith, K. 1968. Functionality of Disengagement in Old Age. Journal of Gerontology. 23: 517-521.

Marshall, V.W. 1985. Conclusions: Ageing and Dying in Pacific Societies, Implications for Theory in Social Gerontology. In D.A. and D.R. Counts (eds.) Ageing and its Transformations. New York: University Press of America. 252-74.

Matcha, D. 2007. The Sociology of Ageing: An International Perspective. New York: Sloan Publishing. 
Mills, C. Wright. 1959. The Sociological Imagination. New York: Oxford University Press.

Mucha, J. and Krzyżowski, Ł.2010. Ageing in Poland at the Dawn of the $21^{\text {st }}$ Century. Polish 2 (170) 10. Sociological Review. ISSN 1231-1413.

National Bureau of Statistics. 2011. Population Ageing and the Generational Economy: A Global Perspective. National Bureau of Statistics, Nigeria.

National Policy on Population for Sustainable Development (NPPSD). 2004. Federal Government of Nigeria.

National Population Commission (NPC). 2009. 2006 Population and Housing Census of the Federal Republic of Nigeria, Priority Table. Abuja: NPC. Vol. 1.

National Population Commission. 2009. Nigeria Gazette.

Neysmith, S. and Edward, J. 1999. Economic depending in the 1990s: Its impact on the third world elderly. Ageing and Society. 14(1): 21-44.

Nyanguru, A.C. 2003. Income Support and the Promotion of the Rights of the Elderly in Lesotho. The African Anthropologist. 10(2).

Parsons, T. 1959. The social structure of the family. In: R. Anslen (ed.). The Family: Its Function and Destiny. New York: Harper. 375.

Peil, M. 1991. Family support for the Nigerian elderly. Journal of Comparative Family Studies. XXII(1): 85-99.

Peil, M. 1995. Family help for the elderly in Africa: A comparative assessment. South African Journal of Gerontology. 4, 26-32.

Peterson, T. 2002. The Mark of Noble Society: a Briefing Paper. Nairobi: Helpage International.

Phillipson, C. 1998. Reconstructing Old Age: New Agendas in Social Theory and Practice. London: SAGE.

Quadagno, J. 1982. Ageing in Early Industrial Society: Work, Family and Social Policy in Nineteenth Century England. New York: Academic Press.

Quadagno, J. 2008. Ageing and the Life Course: An Introduction to Social Gerontology, 5th edition. New York: McGraw Hill.

Schwarz, Anita. 2003. Old Age Security and Social Pensions. World Bank: Human Development (Social Protection) Hub: Processed.

Shanas, E. 1965. National Survey of the Aged. Washington, DC: Government Printing Office. DHSS Pub. No. (OHDS) 83-20425.

Sil, J. 1980. Disengagement Reconsidered: Awareness of finitude. The Gerontologist. 20(4): 457-462.

Smith, J.; Mushati, P.; Kurwa, F.; Mason, P.; Gregson, S. and Lopman, B. 2007. Changing patterns of adult mortality as the HIV epidemic matures in Manicaland, eastern Zimbabwe. AIDS. 21 (supl. 6): 81-6S.

Togonu-Bickersteth, F.; Akinnawo, E.O.; Akinyele, O.S. \& Ayeni, E. 1997. Public alms solicitation among the Yoruba elderly in Nigeria. Southern African. Journal of Gerontology. 6(2): 26-31. 
Togonu-Bickersteth, F. and Akinyemi, A. 2014. Ageing and national development in Nigeria: Costly assumptions and challenges for the future. African Population Studies. Vol. 27, 2 Supp (March).

Treas, J. and Logue, B. 1986. Economic Development and the older population. Population and Development Review. 12: 655-673.

Turner, J.; Beeghley, L. and Powers, C. 1989. The Emergence of Sociological Theory. In Matcha, D. 2007. The Sociology of Ageing: An International Perspective. New York: Sloan Publishing.

UNAIDS. Report on the global AIDS epidemic. 2008. http://www.unaids. org/en/KnowledgeCentre/HIVData/GlobalReport/2008/default.asp.

Unanka, G.O. 2003. Family support and health status of the elderly in Imo State of Nigeria. J Soc Issues. 58: 681-95.

United Nations Economic and Social Commission for Asia and the Pacific. 1994. Ageing and the Family in the Developing Asia and Pacific Countries. New York: United Nations. 73-75.

Utz, R.; Carr, D.; Nesse, R. and Wortman, C. 2002. The Effect of Widowhood on Older Adults' Social participation: An Evaluation of activity, Disengagement, and Continuity Theories. The Gerontologist. 42(4): 522533.

Veblen, T. 1899. The Theory of Leisure Class. In Ritzer, G. 2012. Sociological Theory (8th ed.). New York: McGraw Hill.

Wahab, E.O. 2013. Old-age security provision and life satisfaction among the elderly in Nigeria. The Nigerian Journal of Sociology and Anthropology. 11(2): 23-39.

Wahab, E.O. \& U.C. Isiugo-Abanihe. 2008. An assessment of the importance of children in old age security provisions among the Ijebu of South-West, Nigeria. African Journal for the Psychological Study of Social Issues. 11(1): 46-63.

Wahab, E.O. \& U.C. Isiugo-Abanihe, 2010. Assessing the impact of old age security expectation on elderly persons' achieved fertility in Nigeria. Indian Journal of Gerentology. 24(3): 357-378.

Walker, A. 2006. Re-examining the Political Economy of Ageing: Understanding the Structure/Agency Tension. In Jan Baars, Dale Dannefer, Chris phillipson and Alan Walker (eds). Ageing, Globalization and Inequality: The New Critical Gerontology. Amityville. NY: Bayville. 5980 . 